University of Wollongong

Research Online

Australian Institute for Innovative Materials -

Papers

Australian Institute for Innovative Materials

$1-1-2018$

\title{
Aesthetically Pleasing, Visible Light Transmissive, Luminescent Solar Concentrators Using a BODIPY Derivative
}

\author{
Alina Brzeczek-Szafran \\ University of Wollongong \\ Christopher Richardson \\ University of Wollongong, crichard@uow.edu.au \\ Vanessa Lopez \\ University of Wollongong \\ Pawel W. Wagner \\ University of Wollongong, pawel@uow.edu.au \\ Andrew Nattestad \\ University of Wollongong, anattest@uow.edu.au
}

Follow this and additional works at: https://ro.uow.edu.au/aiimpapers

Part of the Engineering Commons, and the Physical Sciences and Mathematics Commons

Research Online is the open access institutional repository for the University of Wollongong. For further information contact the UOW Library: research-pubs@uow.edu.au 


\title{
Aesthetically Pleasing, Visible Light Transmissive, Luminescent Solar Concentrators Using a BODIPY Derivative
}

\author{
Abstract \\ A visible light transmitting BODIPY derivative with an emission peak at $604 \mathrm{~nm}$ and quantum yield of $64 \%$ \\ is incorporated into a PMMA matrix, resulting in an aesthetically pleasing luminescent solar concentrator \\ (LSC), suitable for "power window" applications. A Monte Carlo modeling platform is shown to be useful \\ firstly to tune device performance, but also to give direction to future synthetic efforts. From this an $4 \mathrm{~mm}$ \\ thick LSC of $(100 \times 100 \mathrm{~mm})$ is shown to have optical efficiency of $\approx 3.3 \%$. \\ Disciplines \\ Engineering | Physical Sciences and Mathematics

\section{Publication Details} \\ Brzeczek-Szafran, A., Richardson, C. J., Lopez, V. M., Wagner, P. \& Nattestad, A. (2018). Aesthetically \\ Pleasing, Visible Light Transmissive, Luminescent Solar Concentrators Using a BODIPY Derivative. \\ Physica Status Solidi (A) Applications and Materials Science, 215 (21), 1800551-1-1800551-6.
}




\title{
Aesthetically Pleasing, Visible Light Transmissive, Luminescent Solar Concentrators Using a BODIPY Derivative
}

\author{
Alina Brzeczek-Szafran, ${ }^{\mathrm{a}, \mathrm{b}}$ Christopher John Richards ${ }^{\mathrm{b}}$, Venassa Maree Lopez ${ }^{\mathrm{b}}$, Pawel Wagner ${ }^{\mathrm{b}}$ and \\ Andrew Nattestad ${ }^{\mathrm{b}}$ * \\ ${ }^{a}$ Faculty of Chemistry, Silesian University of Technology, 44-100 Gliwice, Poland. \\ ${ }^{b}$ ARC Centre of Excellence, Intelligent Polymer Research Institute, University of Wollongong, Australia \\ 2522.
}

\begin{abstract}
A visible light transmitting BODIPY derivative with an emission peak at $604 \mathrm{~nm}$ and quantum yield of $64 \%$ is incorporated into a PMMA matrix, resulting in an aesthetically pleasing luminescent solar concentrator (LSC), suitable for 'power window' applications. A Monte Carlo modelling platform is shown to be useful firstly to tune device performance, but also to give direction to future synthetic efforts. From this an $4 \mathrm{~mm}$ thick LSC of $(100 \mathrm{~mm} \times 100$ $\mathrm{mm}$ ) was shown to have optical efficiency of $3.3 \%$.
\end{abstract}

Luminescent Solar Concentrators (LSCs) were first introduced in the 1970's, where it was envisioned that they could be produced with large form factors and coupled with a minimum of photovoltaic (PV) devices ${ }^{1}$. This was particularly relevant at the time with the high price of PV devices, and offered an alternative to lensed or reflected (e.g. parabolic mirror) concentrators, meaning that they would be able to operate under diffuse lighting conditions, without the requirement of sun tracking and having a low profile (flat design). While one of the recurring aims of much of the early work was to increase the broadband absorption of LSCs, driven by the price of PV modules, recent decreases Si PV cost (as well as thin film technologies such as (dTe) has largely nullified this motivation for creating LSCs (see the "Swanson effect"). LSCs can however fulfil other purposes, which conventional technologies cannot, including "power windows", which incorporate (at least partially) visible light transmissive LSCs ${ }^{2}$. Here the reduced cost of PV actually assists the viability of such systems. As such, LSCs have been touted as an attractive option for buildingintegrated photovoltaics (BIPV). A quick inspection of the AM1.5 spectrum showing almost as high of a photon flux in the $700-1000 \mathrm{~nm}$ as in the $350-700 \mathrm{~nm}$ regions, suggests an strong opportunities for visible light transparent systems ${ }^{3}$. Of course, with transmission of a certain amount of light a prerequisite for 'power window' applications, the attainable solar-to-electric efficiencies of such systems will be limited when compared to opaque PV panels ${ }^{4}$.

Ideal LSC operation involves photoexcitation and reemission (typically fluorescence) from a lumiphore, with the emitted photon waveguided to the edge where a photovoltaic device is attached $^{1}$. A number of factors limit the overall efficiency, such as transmission of incident photons (a factor to be balanced in power windows), non-radiative relaxation and photons not being successfully waveguided to the PV (failing to be internally reflected if they hit the surface at too shallow of an angle, being absorbed by the matrix or scattered from defects). In addition, waveguided photons may be reabsorbed by another lumiphore at which point the photon is subject to all aforementioned obstacles (shown schematically in Figure S1). The extent to which light is downshifted through the process of absorption and reemission (i.e. the Stokes shift) has a strong influence on losses related to reabsorption. A number of reviews cover the basic operation of LSCs along with methods to mitigate the above loss channels. Complimentary to the development of new chromophores/fluorphores, engineering approaches undertaken in order to improve LSC device performance include the use of wavelength selective mirrors \& filters ${ }^{5-6}$, lambertian back reflectors ${ }^{5}$, liquid crystal matrices $^{7-8}$, multi-chromophore systems ${ }^{9}$ with Förster Resonance Energy Transfer (FRET) ${ }^{8,10-11}$, multilayer (with matched PV) ${ }^{5,9,12-13}$, core-shell quantum dots for larger stokes shift ${ }^{14-15}$, and bi-layer (dye + light guide) ${ }^{16-17}$. LSCs are typically composed of glass or glassy polymers, however liquid ${ }^{18}$ and flexible ${ }^{19}$ LSCs have also been realised.

Two metrics commonly used when evaluating LSC performance are the optical $\left(\eta_{\text {opt }}\right)$ and overall solar-to-electric power conversion efficiencies ( $\eta_{\text {PCE }}$ ). The former a ratio of the total photonic power out at the edges divided by that which is incident on the top face of the LSC and the latter term relying upon the PV devices used. The incident power $\left(\mathrm{P}_{\mathrm{in}}\right)$ used is from the AM1.5 spectrum across the whole face of the LSC (although some authors also report $\eta_{\text {opt }}$ as photonic power out divided by photonic power absorbed ${ }^{20}$ or use other light sources ${ }^{21}$ ). For $\eta_{\text {opt }}$, as defined here (see SI for more detail), $P_{\text {out }}$ is the luminous power at the edge, whereas $\eta_{P C E}$ uses the electric power out of PV devices along the edges. Until recently the highest reported $\eta_{P C E}$ was held by Slooff et al. with $7.1 \%$, using an InGaP PV device to effectively utilise the light emitted from their commercially available chromophores ${ }^{9}$.

Crystalline silicon (c-Si) may not be ideal to be incorporated with an LSC. Other large band gap PVs, such as InGaP, have been reported to make more effective use of edge emitted photons; providing higher open circuit voltages $\left(\mathrm{V}_{\mathrm{OC}}\right)^{9}$. Methylammonium lead iodide (MALI) perovskite PV is of interest with demonstrated high $\mathrm{V}_{\mathrm{OC}} \mathrm{S}(>1.2 \mathrm{~V})^{23-24}$.

Despite being widely utilised in other applications due to their strong absorption and luminescence properties ${ }^{26}$, along with synthetic adaptability ${ }^{27}$, boron-dipyrrane (BODIPY) based dyes have only seen limited application in LSCs to date ${ }^{28-30}$. Bailey et al. mixed three BODIPY containing dyes, delivering energy to the red-most emitter through $\mathrm{FRET}^{29}$, while Altan Bozdemir et 
al. similarly used an energy cascade dendrimer system, resulting in panchromatic absorption and emission originating only from the terminal absorber ${ }^{28}$. Although not quantified, this strategy appears to produce intense edge emission. Another, related, approach by Mirloup et al. involved producing dyes with multiple BODIPY moieties ${ }^{30}$, while more recently Davis et. al showed BODIPY functional groups as part of a donor acceptor oligomer ${ }^{31}$. In most of these cases their aesthetic appeal and applicability as power windows is not a primary consideration. Indeed, the majority of high performance LSC-PV systems still utilise dyes which result in a reddish appearance of transmitted light, not dissimilar to what is seen for partially transparent amorphous silicon ${ }^{32}$, Rucomplex based dye-sensitised solar cells ${ }^{33}$ or many of the polymers commonly used in OPVs ${ }^{34-35}$ (although it is noted that visible light transparent OPVs exist ${ }^{36}$ ).

In recent years, a number of researchers have developed NIR absorbing chromophores and employed them in transparent LSCs. High performances, however, have been difficult to realise due to limited luminescence. Results achieved by Lunt's group harvesting NIR photons using a LSC based on fluorescent organic salts showed a $\eta_{\text {PCE }}$ of $0.4 \%^{37}$. While QD based LSCS were demonstrated by Meinardi et. al. with an $\eta_{\text {opt }}$ of $3.27 \%^{38}$ and further improved upon by Chen et al. (3.94\%) ${ }^{39}$ and Zhou et al. $(6.1 \%)^{15}$. These tend to have a yellow/brown tint, which has been noted to be less aesthetically appealing ${ }^{4}$.

The BODIPY derivative reported here absorbs and emits in the red / near infrared part of the solar spectrum, and wide optical window in the blue, green and yellow parts. As mentioned, the PV device in the integrated system can be selected in order to make best use of the LSC output spectrum. In this work we model our LSC with a number of different PV technologies, in conjunction with the measured output. In the case of the dye presented here, the majority of light emitted at the edge is in the $600-750 \mathrm{~nm}$ range, making MALI and GaAs attractive options (where thermalisation losses will be less than for $\mathrm{c}-\mathrm{Si}$ ). This is discussed in more detail later. We also look to the future possibilities of BODIPY dyes, with simulated performances for LSCs made with larger Stokes shifts and/or higher photoluminescence quantum yields (PLQY).

Dye I was synthesised based on a previously reported material $^{40}$, via Knoevenagel condensation of tetramethyl BODIPY derivative with carbazole-3-carbaldehyde, with the full synthetic description reported elsewhere ${ }^{41}$. Optical properties of dye I were characterised for dilute solutions in MMA (Aldrich), with an absorption maximum at $586 \mathrm{~nm}$ (Shimadzu UV-1800), emission peak at $604 \mathrm{~nm}$ (Horiba Florohub), which translates to the Stokes shift of $509 \mathrm{~cm}^{-1}(18 \mathrm{~nm}$, Figure 1). The dye exhibits high molar extinction coefficient of $\sim 110,000 \mathrm{M}^{-1}$ $\mathrm{cm}^{-1}$ and a PLQY (measured with integrating sphere attachment) of $64 \pm 1 \%$. High PLQY values are particularly important for LSC applications as it drastically increases performance.

A PMMA:MMA (5:18 weight ratio) syrup was produced and dye added (to give 15 or $60 \mu \mathrm{M}$ ), based on the syrup mass and density of PMMA $\left(1.18 \mathrm{~g} / \mathrm{cm}^{3}\right)$. After the dye was thoroughly mixed through, an initiator, Azobisisobutyronitrile solution
(AIBN, 768375 Aldrich) was added at $3.4 \mu \mathrm{L} / \mathrm{g}$ of syrup. The initiated syrup was then injected into a gap in the gasket of a mould comprised of two glass sheets, separated using low odour rubber (LST group, Australia). The gap in the gasket was then closed and left to settle before being immersed in a water bath at $50{ }^{\circ} \mathrm{C}$ for 72 hours, followed by annealed at $120{ }^{\circ} \mathrm{C}$ for 2 hours $\left(2^{\circ} \mathrm{C} / \mathrm{hr}\right.$ ramp each way) and the surfaces polished to < $3 \mu \mathrm{m}$ surface flatness, using a rotary polishing system (Struers Tegramin-25) and diamond paste (Struers DP lubricant green). Polymerisation resulted in a slight red shift of both absorption and emission (also in Figure 1), with the peak absorbance and emission at $590 \mathrm{~nm}$ and $608 \mathrm{~nm}$ respectively (emission in PMMA was collected in front facing mode to minimise reabsorption effects). Preliminary empirical calculations suggested $60 \mu \mathrm{M}$ was an optimal dye concentration for this slab thickness (although this was a broad maximum) and 15 $\mu \mathrm{M}$ was predicted to also produce an efficient LSC. The broad optimum concentration is promising for organic dye based LSCs, as it allows a greater degree of flexibility for aesthetic considerations.

The LSC was illuminated using simulated sunlight from a Xe lamp (Oriel), filtered to approximate the AM1.5 spectrum. Edge emission spectra were measured using an Ocean Optics HR4000 spectrometer, while the intensity was quantified using a calibrated Hamamatsu S1337-1010BR Si photodiode pressed against the edge of the LSC. Areal dependence of $\eta_{\text {opt }}$ was measured (see in Figure S3) through the use of shadow masks. Digital photographs of the University of Wollongong are shown in Figures $2 \mathrm{~b}-\mathrm{d}$ without (b) and with either the $15 \mu \mathrm{M}$ (c) or 60 $\mu M$ (d) LSC in front of the camera. The transmission of visible light corresponds well with expectation, given the low extinction coefficients of Dye $I$ in the $400-550 \mathrm{~nm}$ region of the spectrum seen in Figure 1. Again, this highlights the suitability for architectural purposes, particularly at lower concentrations. Furthermore, even under modest lighting conditions an intense deep red glow is seen at the edge of the LSC plate (Figure 2a). The CIEL*a*b* co-ordinates (D65 illuminant) for these LSCs were measured to be $(83.06,5.71$, 18.6) and (52.93, 40.15, -48.15) for the low and high concentrations, leading to CCT values of $7759 \mathrm{~K}$ and $7520 \mathrm{~K}$ respectively ${ }^{42}$.

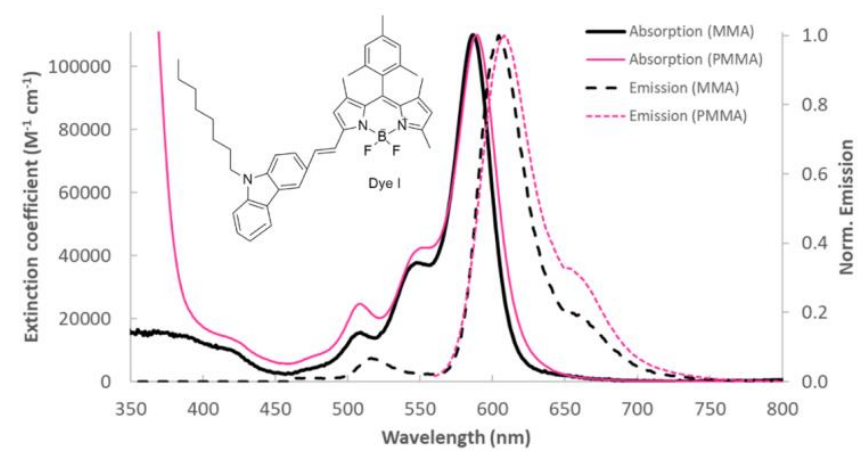

Figure 1. Absorption and emission spectra of dye $\mathrm{I}$, measured as dilute in methyl methacrylate and in PMMA matrix. The chemical structure of dye I is shown as
an inset. 
The $100 \times 100 \times 4 \mathrm{~mm}$ LSC was illuminated at the top face using simulated AM1.5 light while the spectrum of light outputted at the edges was measured using the HR4000 spectrometer. Edge emission was seen to be considerably redshifted as compared to the emission of Dye $\mathbf{I}$ in dilute MMA, which was ascribed to significant reabsorption of emitted light on account of overlap between the emission and absorption spectra of the dyes. Figure 3a shows the measured output spectra from the LSC plate with the whole area exposed, along with when it is partially shaded and the dilute solution spectrum again for reference. The shift in the emission peak is ascribed to reabsorption effects. When the LSC slab is masked, it is seen that with higher dye concentrations the edge emission spectra are both more red-shifted and more size dependent.
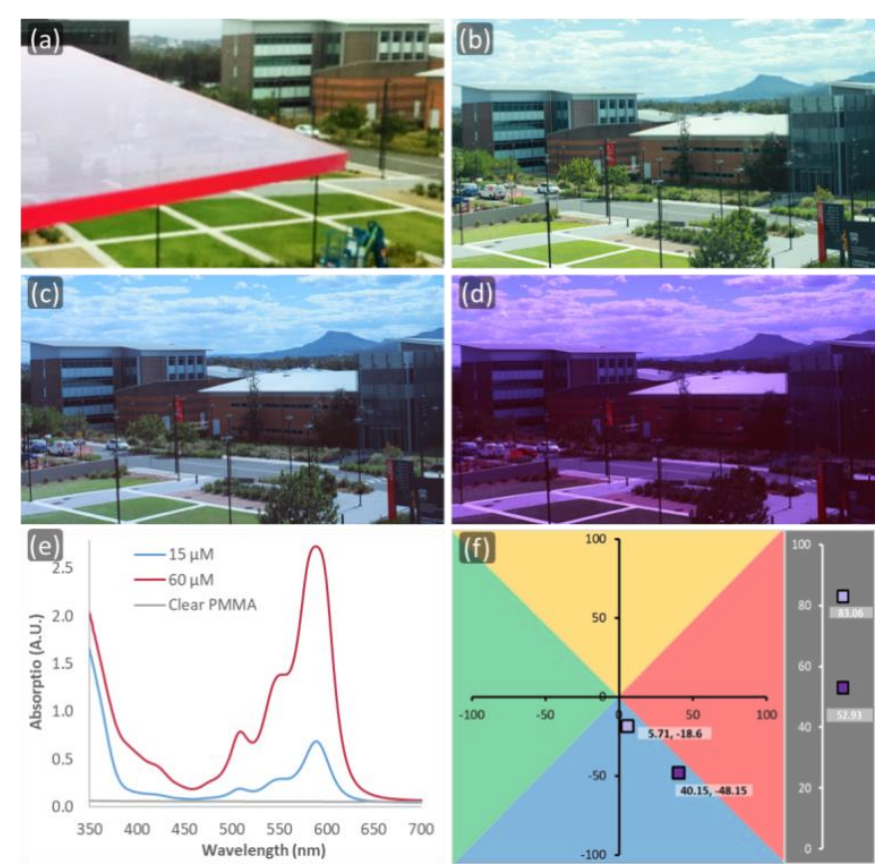

Figure 2. Digital photographs of (a) the $15 \mu \mathrm{M}$ LSC with the emissive edge angled towards the camera, (b) the UOW Innovation Campus, unfiltered, (c) UOW Innovation Campus through the $15 \mu \mathrm{M}$ LSC "window" and (d) UOW Innovatio Campus through the $60 \mu \mathrm{M}$ LSC "window" The camera settings for (b) - (d) wer locked to ensure direct comparability - $1 / 320$ s exposure time, F7.1, ISO400 and autofocus on a Canon EOS 70OD SLR camera. (e) Absorption spectra of the two LSCS along with a clear PMMA sheet for comparison. (f) Lab space representation
of LSC slabs in transmission mode using HunterLab ColorQuest XE.

The optical efficiency $\left(\eta_{\text {opt }}\right)$ was calculated, based on the measured emission and the observed intensity, to be around $2.7 \%$ for illumination of the full plate of the lower dye loading, $3.3 \%$ for the higher concentration, and up to $5.1 \%$ for small areas and high concentrations (Figure $3 \mathrm{~b}$ ). It is interesting to again note the differences in size dependences for the two concentrations used here, as the lower loading is able to provide both similar efficiencies at $100 \times 100 \mathrm{~mm}$, while maintaining better transmission across the visible spectrum (seen by comparing Figures $2 \mathrm{c}$ and $2 \mathrm{~d}$ ). Although these are some of the highest reported $\eta_{\text {opt }}$ values for visible light transparent systems, the geometric dependence suggests that ultimately this metric may have limited utility as a means of comparing dyes with no agreed upon standard dimensions. The high observed optical efficiencies for small (such as those with $2 \mathrm{~cm}$ edge length) are not expected to be particularly practical for the stated purpose of power windows. We note here that this metric can also be gamed. For example, a $100 \times$ $100 \times 100 \mathrm{~mm}$ block with have $\eta_{\text {opt }}$ several times higher than the optimised $100 \times 100 \times 4 \mathrm{~mm}$ plate. Fortunately, this practice does not seem to be happening at present, however, it suggests the need for better quantification approaches.

Using the emission profiles and intensities reported above, in conjunction with reported Incident Photon to Charge Carrier Efficiencies (IPCE), Fill Factors (FF) and Open Circuit Voltages $\left(\mathrm{V}_{\mathrm{OC}}\right)$, predicted PCEs were obtained. From Table 1 , it can be seen that InGaP, used in other high voltage LSC + PV systems, will not be particularly useful here as its $1.88 \mathrm{eV}$ bandgap means it cannot capture the bulk of the emission from the
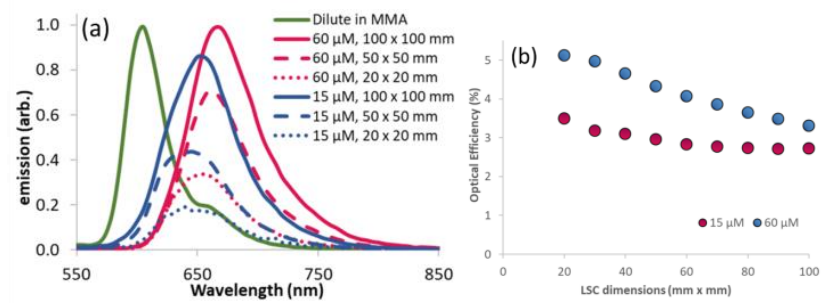

Figure 3. (a) Output spectra of LSCs of different sizes and dye loadings. Edge emission spectra intensities were scaled based on Si diode responses. (b) Calculated optical efficiencies.

edge of the dye I based LSC. More so, in spite of the slightly higher $\eta_{\text {opt }}$ for the $60 \mu \mathrm{M}$ LSC, the redshifted emission results in a lower $\eta_{P C E}$ for InGaP than for the $15 \mu \mathrm{M}$ plate. Although the highest $\eta_{P C E}$ values were observed when coupling with GaAs, it remains expensive. On the other hand, perovskites have been predicted to be a very cheap form of $\mathrm{PV}^{43}$. Furthermore, the development of this technology suggests that a substantial amount of optimization may be carried out in the near future and the efficiencies used in this estimation will probably soon be improved upon - affording even higher performance power window systems.

Monte Carlo modelling was employed to predict the efficiencies of systems of hypothetical dyes consisting of modified optical properties of dye I. A computational model was developed, representing components of the physical LSC system. The AM1.5 spectrum was used to generate the proportions of photons. Individual photons were then traced through the internal volume of the simulated LSC, entering the LSC from the top face alike the experimental setup. Randomised absorption and emission events occurred based on the measured dye properties. Internal reflection also occurred if the photon reached a boundary at above a critical angle. Photons that reached a boundary edge were terminated and their contribution to the output power was recorded. This model is explained in further detail in the SI (S4), with code available at www.github.com/PhotonFiend/LSC.

Table 1. Predicted efficiencies based on state-of-the-art PV devices and the two LSCs described here.

\begin{tabular}{l|ll|c|c|c}
\hline \multirow{2}{*}{ Device } & \multirow{2}{*}{$\begin{array}{c}\mathrm{V}_{\mathrm{OC}}(\mathrm{V}) \\
{[\mathrm{a}]}\end{array}$} & $\mathrm{FF}$ & \multicolumn{2}{|c|}{$15 \mu \mathrm{M}$ LSC } & \multicolumn{2}{|c}{$60 \mu \mathrm{M}$ LSC } \\
\cline { 3 - 5 } & & $\begin{array}{c}J_{S C} \\
\left(\mathrm{~mA} / \mathrm{cm}^{2}\right)^{[}\end{array}$ & $\begin{array}{c}\eta_{\mathrm{PCE}} \\
(\%)^{[\mathrm{cc}]}\end{array}$ & $\begin{array}{c}J_{S C} \\
\left(\mathrm{~mA} / \mathrm{cm}^{2}\right)\end{array}$ & $\begin{array}{c}\eta_{P C E} \\
(\%)^{[c]}\end{array}$
\end{tabular}




\begin{tabular}{c|cc|c|c|c|c}
\hline & & & $b]$ & & {$[b]$} & \\
\hline $\mathrm{Si}$ & $0.740^{44}$ & $0.827^{44}$ & $8.73^{45}$ & 0.84 & $10.96^{45}$ & 1.05 \\
$\mathrm{GaAs}$ & $1.122^{44}$ & $0.865^{44}$ & $8.56^{46}$ & 1.31 & $10.69^{46}$ & 1.63 \\
InGaP & $1.390^{47}$ & $0.860^{47}$ & $3.16^{48}$ & 0.60 & $2.37^{48}$ & 0.45 \\
$\mathrm{MALI}$ & $1.130^{49}$ & $0.750^{49}$ & $8.00^{49}$ & 1.07 & $9.92^{49}$ & 1.32 \\
\hline
\end{tabular}

VOC and FF taken as 1 sun values from literature sources. JSC based on the integration of device EQE (literature) over emission spectra of the LSC (as per Figure 3). Pout is average power density out along edges, based on calculated JSC, while the overall efficiency takes into account the total illumination area. [a] Note that in calculating the efficiency, VOC is scaled in accordance with $\mathrm{J}_{\mathrm{SC}}$ compared to reported 1 sun $\mathrm{J}_{\mathrm{SC}}$ values $(60 \mathrm{mV} /$ decade of light intensity). [b] $\mathrm{J}_{\mathrm{SC}}$ calculated for the attached PV strip.

Increased Stokes shifts of 10, 20 and $30 \mathrm{~nm}$ were modelled, along with PLQY values of 80 and $90 \%$ (Table 2). In order to simulate an increased Stokes shift, the emission spectrum of

Table 2. Predicted enhancements to the optical efficiency of an LSC made with a dye similar to I, but with a larger stokes shift and/or enhanced emission yield.

\begin{tabular}{ll}
\hline A19m 'modification' & Relative increase (\%) in $\eta_{\mathrm{opt}}$ \\
\hline$+5 \mathrm{~nm}$ stokes & +10.6 \\
$+10 \mathrm{~nm}$ stokes & +23.8 \\
$+20 \mathrm{~nm}$ stokes & +51.3 \\
$70 \%$ PLQY & +20.9 \\
$80 \%$ PLQY & +76.7 \\
$90 \%$ PLQY & +190.8 \\
$+20 \mathrm{~nm}$ stokes; 90\% PLQY & +285.8 \\
\hline
\end{tabular}

dye I was translated, with all other spectroscopic properties unaltered. The geometry is kept at $100 \times 100 \times 4 \mathrm{~mm}$ for these simulations.

As expected, modelling data, shown in Table 2 and Figure S3(c \& d), indicates that increases in either Stokes shift or PLQY will give more efficient LSCs. An interesting observation here is that the magnitude of the predicted increase is strongly dependent upon the PLQY, and as such, more effort should be invested in synthetic strategies to raise this value. Even with most optimistic conditions modelled here, the enhancement will still only provide modest overall $\eta_{\text {PCE }}$ values. As such, broadening the absorption range also appears to be a necessary goal (although not specifically modelled here). Further enhancement can be expected from optical management techniques, such as dichroic coatings, which were not incorporated here. It is also noteworthy that with enhanced PLQY and Stokes shifts, the optimal concentrations increase.

In summary, BODIPY containing Dye I, was demonstrated to be a promising dye for LSC applications, when incorporated in a PMMA matrix. This performance is attributed to a combination of PLQY (64 \%) and a Stokes shift of $16 \mathrm{~nm}$. A $100 \times 100 \times 4$ $\mathrm{mm}$ slab, containing $60 \mu \mathrm{M}$ of Dye I was shown to have an optical efficiency in excess of $3.3 \%$, with a calculated $\eta_{\text {PCE }}$ of $1.63 \%$ when paired with GaAs, while a lower dye loading of 15 $\mu \mathrm{M}$ gave only slightly lower efficiency and high visible light transmission. It was however seen that, in spite of this performance, there is still significant room for improvement.
Particularly through synthetic strategies aimed towards increasing the emission yield of the dye.

\section{Conflicts of interest}

The Authors declare no conflicts of interest.

\section{Supporting Information}

Supporting Information is available from the Wiley Online Library or from the author.

Received: ((will be filled in by the editorial staff))

Revised: ((will be filled in by the editorial staff))

Published online: ((will be filled in by the editorial staff))

\section{Notes and references}

1. Weber, W. H.; Lambe, J., Luminescent Greenhouse Collector for Solar-Radiation. Applied Optics 1976, 15 (10), 2299-2300. 2. Debije, M. G.; Verbunt, P. P. C., Thirty Years of Luminescent Solar Concentrator Research: Solar Energy for the Built Environment. Advanced Energy Materials 2012, 2 (1), 12-35. 3. International, A., Standard Tables for Reference Solar Spectral Irradiances: Direct Normal and Hemispherical on $37^{\circ}$ Tilted Surface. ASTM international: 2012; Vol. G-173.

4. Traverse, C. J.; Pandey, R.; Barr, M. C.; Lunt, R. R., Emergence of highly transparent photovoltaics for distributed applications. Nature Energy 2017, 2 (11), 849-860.

5. Goldschmidt, J. C.; Peters, M.; Bosch, A.; Helmers, H.; Dimroth, F.; Glunz, S. W.; Willeke, G., Increasing the efficiency of fluorescent concentrator systems. Solar Energy Materials and Solar Cells 2009, 93 (2), 176-182.

6. Verbunt, P. P. C.; Tsoi, S.; Debije, M. G.; Broer, D. J.;

Bastiaansen, C. W. M.; Lin, C. W.; de Boer, D. K. G., Increased efficiency of luminescent solar concentrators after application of organic wavelength selective mirrors. Optics Express 2012, 20 (19), A655-A668.

7. MacQueen, R. W.; Cheng, Y. Y.; Clady, R.; Schmidt, T. W., Towards an aligned luminophore solar concentrator. Optics Express 2010, 18 (13), A161-A166.

8. MacQueen, R. W.; Schmidt, T. W., Molecular Polarization Switching for Improved Light Coupling in Luminescent Solar Concentrators. Journal of Physical Chemistry Letters 2013, 4 (17), 2874-2879.

9. Slooff, L. H.; Bende, E. E.; Burgers, A. R.; Budel, T.; Pravettoni, M.; Kenny, R. P.; Dunlop, E. D.; Buchtemann, A., A luminescent solar concentrator with $7.1 \%$ power conversion efficiency. Physica Status Solidi-Rapid Research Letters 2008, 2 (6), 257-259. 10. Tummeltshammer, C.; Taylor, A.; Kenyon, A. J.;

Papakonstantinou, I., Homeotropic alignment and Forster resonance energy transfer: The way to a brighter luminescent solar concentrator. Journal of Applied Physics 2014, 116 (17), 173103.

11. Liu, C.; Li, B., Multiple dyes containing luminescent solar concentrators with enhanced absorption and efficiency. Journal of Optics 2015, 17 (2), 025901.

12. Minei, P.; Fanizza, E.; Rodriguez, A. M.; Munoz-Garcia, A. B.; Cimino, P.; Pavone, M.; Pucci, A., Cost-effective solar concentrators based on red fluorescent $\mathrm{Zn}(\mathrm{II})$-salicylaldiminato complex. Rsc Advances 2016, 6 (21), 17474-17482.

13. Turrisi, R.; Sanguineti, A.; Sassi, M.; Savoie, B.; Takai, A.; Patriarca, G. E.; Salamone, M. M.; Ruffo, R.; Vaccaro, G.; Meinardi, F.; Marks, T. J.; Facchetti, A.; Beverina, L., Stokes shift/emission efficiency trade-off in donor-acceptor 
perylenemonoimides for luminescent solar concentrators. Journal of Materials Chemistry A 2015, 3 (15), 8045-8054. 14. Li, C.; Chen, W.; Wu, D.; Quan, D. H.; Zhou, Z. M.; Hao, J. J.; Qin, J.; Li, Y. W.; He, Z. B.; Wang, K., Large Stokes Shift and High Efficiency Luminescent Solar Concentrator Incorporated with CulnS 2 /ZnS Quantum Dots. Scientific Reports 2015, 5, 17777. 15. Zhou, Y.; Benetti, D.; Fan, Z.; Zhao, H.; Ma, D.; Govorov, A. O.; Vomiero, A.; Rosei, F., Near Infrared, Highly Efficient Luminescent Solar Concentrators. Advanced Energy Materials 2016, 6 (11), 1501913.

16. Currie, M. J.; Mapel, J. K.; Heidel, T. D.; Goffri, S.; Baldo, M. A., High-efficiency organic solar concentrators for photovoltaics. Science 2008, 321 (5886), 226-228.

17. Tsoi, S.; Broer, D. J.; Bastiaansen, C. W. M.; Debije, M. G., Patterned dye structures limit reabsorption in luminescent solar concentrators. Optics Express 2010, 18 (23), A536-A543.

18. Filloux, A.; Mugnier, J.; Bourson, J.; Valeur, B., Fluorescent Solar Concentrators Using Liqui Solutions. Revue De Physique Appliquee 1983, 18 (5), 273-279.

19. Correia, S. F. H.; Lima, P. P.; André, P. S.; Ferreira, M. R. S.; Carlos, L. A. D., High-efficiency luminescent solar concentrators for flexible waveguiding photovoltaics. Solar Energy Materials and Solar Cells 2015, 138, 51-57.

20. Zhang, B.; Soleimaninejad, H.; Jones, D. J.; White, J. M.; Ghiggino, K. P.; Smith, T. A.; Wong, W. W. H., Highly Fluorescent Molecularly Insulated Perylene Diimides: Effect of Concentration on Photophysical Properties. Chemistry of Materials 2017, 29 (19), 8395-8403.

21. Gianfaldoni, F.; De Nisi, F.; lasilli, G.; Panniello, A.; Fanizza, E.; Striccoli, M.; Ryuse, D.; Shimizu, M.; Biver, T.; Pucci, A., A pushpull silafluorene fluorophore for highly efficient luminescent solar concentrators. RSC Advances 2017, 7 (59), 37302-37309. 22. Shockley, W.; Queisser, H. J., Detailed Balance Limit of Efficiency of p-n Junction Solar Cells. J. Appl. Phys. 1961, 32 (3), 10.

23. Kojima, A.; Teshima, K.; Shirai, Y.; Miyasaka, T., Organometal Halide Perovskites as Visible-Light Sensitizers for Photovoltaic Cells. Journal of the American Chemical Society 2009, 131 (17), 6050-6051.

24. Lee, M. M.; Teuscher, J.; Miyasaka, T.; Murakami, T. N.; Snaith, H. J., Efficient Hybrid Solar Cells Based on MesoSuperstructured Organometal Halide Perovskites. Science 2012, 338 (6107), 643-647.

25. Edri, E.; Kirmayer, S.; Kulbak, M.; Hodes, G.; Cahen, D., Chloride Inclusion and Hole Transport Material Doping to Improve Methyl Ammonium Lead Bromide Perovskite-Based High Open-Circuit Voltage Solar Cells. The Journal of Physical Chemistry Letters 2014, 5 (3), 429-433.

26. Loudet, A.; Burgess, K., BODIPY Dyes and Their Derivatives: Syntheses and Spectroscopic Properties. Chemical Reviews 2007, 107 (11), 4891-4932.

27. Boens, N.; Verbelen, B.; Dehaen, W., Postfunctionalization of the BODIPY Core: Synthesis and Spectroscopy. European Journal of Organic Chemistry 2015, 2015 (30), 6577-6595.

28. Altan Bozdemir, O.; Erbas-Cakmak, S.; Ekiz, O. O.; Dana, A.; Akkaya, E. U., Towards Unimolecular Luminescent Solar Concentrators: Bodipy-Based Dendritic Energy-Transfer Cascade with Panchromatic Absorption and Monochromatized Emission. Angewandte Chemie International Edition 2011, 50 (46), 1090710912.

29. Bailey, S. T.; Lokey, G. E.; Hanes, M. S.; Shearer, J. D. M.; McLafferty, J. B.; Beaumont, G. T.; Baseler, T. T.; Layhue, J. M.; Broussard, D. R.; Zhang, Y.-Z.; Wittmershaus, B. P., Optimized excitation energy transfer in a three-dye luminescent solar concentrator. Solar Energy Materials and Solar Cells 2007, 91 (1), 67-75.
30. Mirloup, A.; Retailleau, P.; Ziessel, R., Luminescent molecular solar concentrators made of multi-Bodipy dyes. Tetrahedron Letters 2013, 54 (33), 4456-4462.

31. Davis, N. J. L. K.; MacQueen, R. W.; Jones, S. T. E.; OrofinoPena, C.; Cortizo-Lacalle, D.; Taylor, R. G. D.; Credgington, D.; Skabara, P. J.; Greenham, N. C., Star-shaped fluorene-BODIPY oligomers: versatile donor-acceptor systems for luminescent solar concentrators. Journal of Materials Chemistry C 2017, 5 (8), 1952-1962.

32. Yang, Y.; O’Brien, P. G.; Ozin, G. A.; Kherani, N. P., Seethrough amorphous silicon solar cells with selectively transparent and conducting photonic crystal back reflectors for building integrated photovoltaics. Applied Physics Letters 2013, 103 (22), 221109

33. O'Regan, B.; Gratzel, M., A low-cost, high-efficiency solar cell based on dye-sensitized colloidal $\mathrm{TiO}_{2}$ films. Nature 1991, 353 (6346), 737-740.

34. Tao, C.; Xie, G.; Liu, C.; Zhang, X.; Dong, W.; Meng, F.; Kong, X.; Shen, L.; Ruan, S.; Chen, W., Semitransparent inverted polymer solar cells with $\mathrm{MoO}_{3} / \mathrm{Ag} / \mathrm{MoO}_{3}$ as transparent electrode. Applied Physics Letters 2009, 95 (5), 053303. 35. Ng, G.-M.; Kietzke, E. L.; Kietzke, T.; Tan, L.-W.; Liew, P.-K.; Zhu, F., Optical enhancement in semitransparent polymer photovoltaic cells. Applied Physics Letters 2007, 90 (10), 103505. 36. Chen, C. C.; Dou, L. T.; Zhu, R.; Chung, C. H.; Song, T. B.; Zheng, Y. B.; Hawks, S.; Li, G.; Weiss, P. S.; Yang, Y., Visibly Transparent Polymer Solar Cells Produced by Solution Processing. Acs Nano 2012, 6 (8), 7185-7190.

37. Zhao, Y. M.; Meek, G. A.; Levine, B. G.; Lunt, R. R., NearInfrared Harvesting Transparent Luminescent Solar Concentrators. Advanced Optical Materials 2014, 2 (7), 606-611. 38. Meinardi, F.; McDaniel, H.; Carulli, F.; Colombo, A.; Velizhanin, K. A.; Makarov, N. S.; Simonutti, R.; Klimov, V. I.; Brovelli, S., Highly efficient large-area colourless luminescent solar concentrators using heavy-metal-free colloidal quantum dots. Nat Nano 2015, 10 (10), 878-885.

39. Chen, W.; Li, J.; Liu, P.; Liu, H.; Xia, J.; Li, S.; Wang, D.; Wu, D.; Lu, W.; Sun, X. W.; Wang, K., Heavy Metal Free Nanocrystals with Near Infrared Emission Applying in Luminescent Solar Concentrator. Solar RRL 2017, 1 (6), 1700041.

40. Zhang, D.; Martin, V.; Garcia-Moreno, I.; Costela, A.; PerezOjeda, M. E.; Xiao, Y., Development of excellent long-wavelength BODIPY laser dyes with a strategy that combines extending [small pi]-conjugation and tuning ICT effect. Physical Chemistry Chemical Physics 2011, 13 (28), 13026-13033.

41. Kurowska, A.; Brzeczek-Szafran, A.; Domagala, W.; Zassowski, P.; Lapkowski, M.; Wagner, P.; Wagner, K., Mono and disubstituted BODIPY with electrondonating carbazole, thiophene, and 3,4-ethylenodioxythiophene units. Electrochimica Acta 2018, 271, 685-698.

42. Illumination, C. o. Technical Report: Colorimetry; Government of the United States of America: 2004.

43. Cai, M.; Wu, Y.; Chen, H.; Yang, X.; Qiang, Y.; Han, L., CostPerformance Analysis of Perovskite Solar Modules. Advanced Science 2017, 4 (1), 1600269.

44. Green, M. A.; Emery, K.; Hishikawa, Y.; Warta, W.; Dunlop, E. D., Solar cell efficiency tables (version 46). Progress in Photovoltaics: Research and Applications 2015, 23 (7), 805-812. 45. Santbergen, R.; Mishima, R.; Meguro, T.; Hino, M.; Uzu, H.; Blanker, J.; Yamamoto, K.; Zeman, M., Minimizing optical losses in monolithic perovskite/c-Si tandem solar cells with a flat top cell. Optics Express 2016, 24 (18), A1288-A1299. 46. Bauhuis, G. J.; Mulder, P.; Haverkamp, E. J.; Huijben, J. C. C. M.; Schermer, J. J., 26.1\% thin-film GaAs solar cell using epitaxial lift-off. Solar Energy Materials and Solar Cells 2009, 93 (9), 14881491. 
47. Takamoto, T.; Ikeda, E.; Kurita, H.; Ohmori, M., Structural optimization for single junction InGaP solar cells. Solar Energy Materials and Solar Cells 1994, 35, 25-31.

48. Sato, S.-i.; Ohshima, T.; Imaizumi, M., Modeling of degradation behavior of InGaP/GaAs/Ge triple-junction space solar cell exposed to charged particles. Journal of Applied Physics 2009, 105 (4), 044504.

49. Yang, W. S.; Noh, J. H.; Jeon, N. J.; Kim, Y. C.; Ryu, S.; Seo, J.; Seok, S. I., High-performance photovoltaic perovskite layers fabricated through intramolecular exchange. Science 2015, 348 (6240), 1234-1237. 


\title{
Supporting information for: Aesthetically Pleasing, Visible Light Transmissive, Luminescent Solar Concentrators Using a BODIPY Derivative
}

\author{
Alina Brzeczek-Szafran ${ }^{\wedge 1,2}$, Chris Richards $\wedge^{\wedge}$, Vanessa Lopez ${ }^{2}$, Pawel Wagner ${ }^{2}$, Andrew Nattestad ${ }^{2 *}$ \\ [1] Faculty of Chemistry, Silesian University of Technology, 44-100 Gliwice, Poland; [2] ARC Centre of Excellence, Intelligent \\ Polymer Research Institute, University of Wollongong, Australia 2522 \\ $\wedge$ These authors contributed equally to this work \\ *Corresponding author: anattest@uow.edu.au
}




\section{S1. Overview of processed in LSC operation}

The individual steps involved in LSC operation are outlined below in Figure S1. This was used to inform our Monte-Carlo modelling (below in section S4).

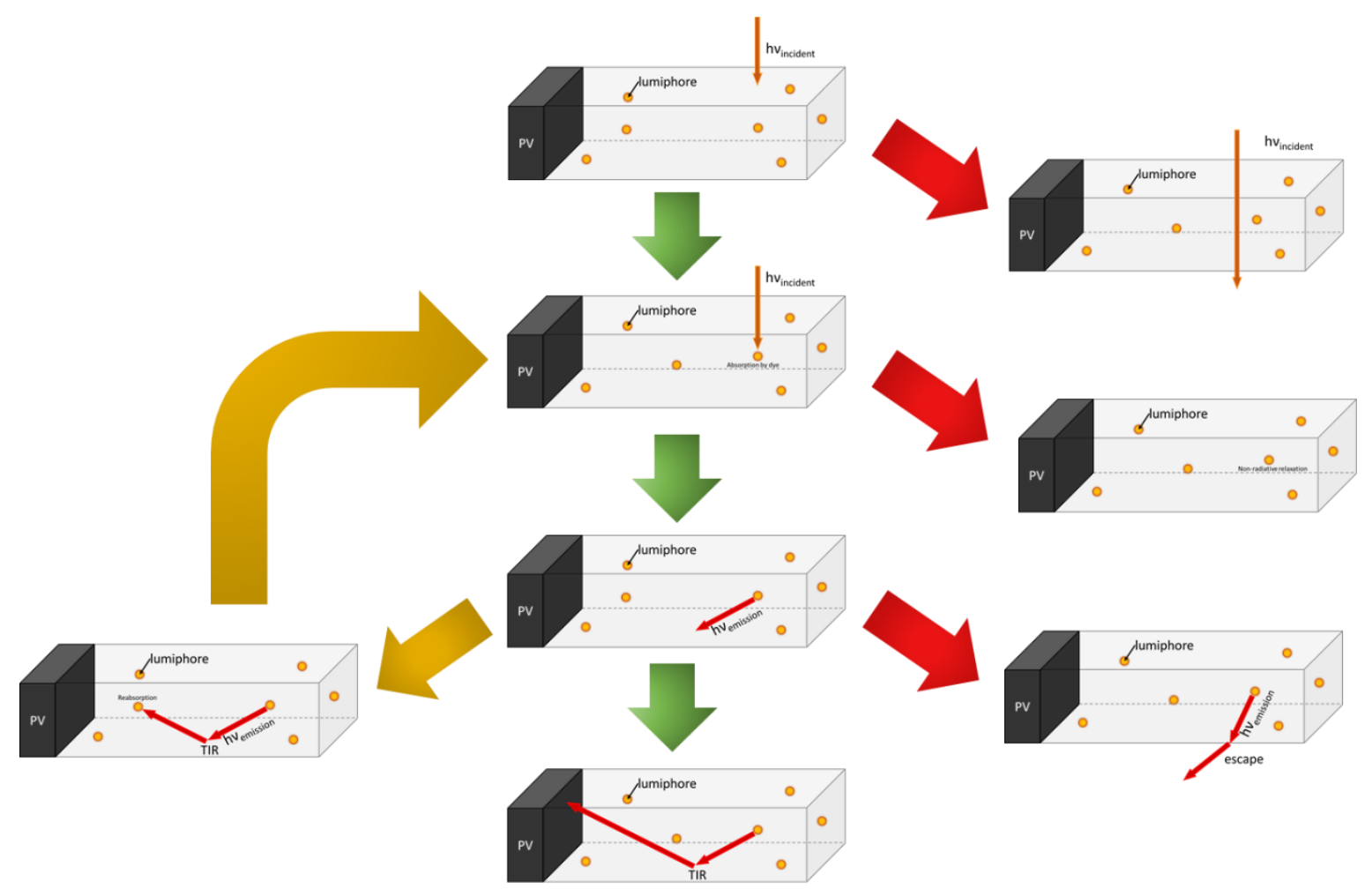

Figure S1 - Schematic of LSC operating principles 


\section{S2. Calculation of $\eta_{\text {opt }}$}

The optical efficiency, that is the ratio of photonic power out $\left(P_{\text {out }}\right)$ over the input $\left(P_{\text {in }}\right)$, can be calculated based on the intensity and wavelength of light, as observed at the edges of the LSC panel.

$$
\eta_{\text {opt }}=\frac{P_{\text {out }}}{P_{\text {in }}}, P_{\text {in }}=A M 1.5
$$

This involved measuring the wavelength distribution of photons, in accordance with an ocean optics spectrometer measured EQE for each corresponding wavelength, based on the assumption that all edge emitted light (from the $1 \mathrm{~cm}$ wide, $4 \mathrm{~mm}$ high section to which the diode was pressed) was absorbed by said diode. The energies of the emitted photons were then factored in and the total optical power out determined. This was then divided by the simulated AM1.5G light used as input (100 mW/cm ${ }^{2}$ from a Xe arc lamp - Oriel).

- An Ocean Optics HR4000 spectrophotometer was used to measure the output spectrum in a semi-quantitative manner.

- The short circuit current density of the Si diode, placed against the edge of the LSC, along with its measured EQE (such that the sensitivity to light of any wavelength is known) and the spectral information mentioned above mean that the edge emission can be quantified.

- This was used, in conjunction with literature results of photovoltaic devices, to calculate the predicted short circuit current density (integrating the reported EQE over the LSC output spectra). In turn, this was used to calculate a predicted efficiency $\left(\eta_{\mathrm{PCE}}\right)$, again using literature values for fill factor and open circuit voltage. It should be noted here that the lower $\mathrm{J}_{\mathrm{SC}} \mathrm{e}_{\mathrm{OC}}$ than the literature values. $\mathrm{V}_{\mathrm{OC}}$ values have been adjusted in accordance with a typical $60 \mathrm{mV}$ shift per decade of intensity. FF has not been adjusted, however it is anticipated that this only change slightly within the light intensity range observed here.

1. Leow, S.W., et al., Analyzing luminescent solar concentrators with front-facing photovoltaic cells using weighted Monte Carlo ray tracing. Journal of Applied Physics, 2013. 113(21): p. 214510.

2. Şahin, D., B. Ilan, and D.F. Kelley, Monte-Carlo simulations of light propagation in luminescent solar concentrators based on semiconductor nanoparticles. Journal of Applied Physics, 2011. 110(3): p. 033108. 


\section{S3-Partial masking, examining small area responses}

Although $\eta_{\text {opt }}$ has been widely adopted as a metric for comparing LSCs, it does have a size dependence. To explore this, a series of masks were applied to our LSC testing apparatus (Fig S3(a) below). The two schematics on the right illustrate a larger and small exposed area.
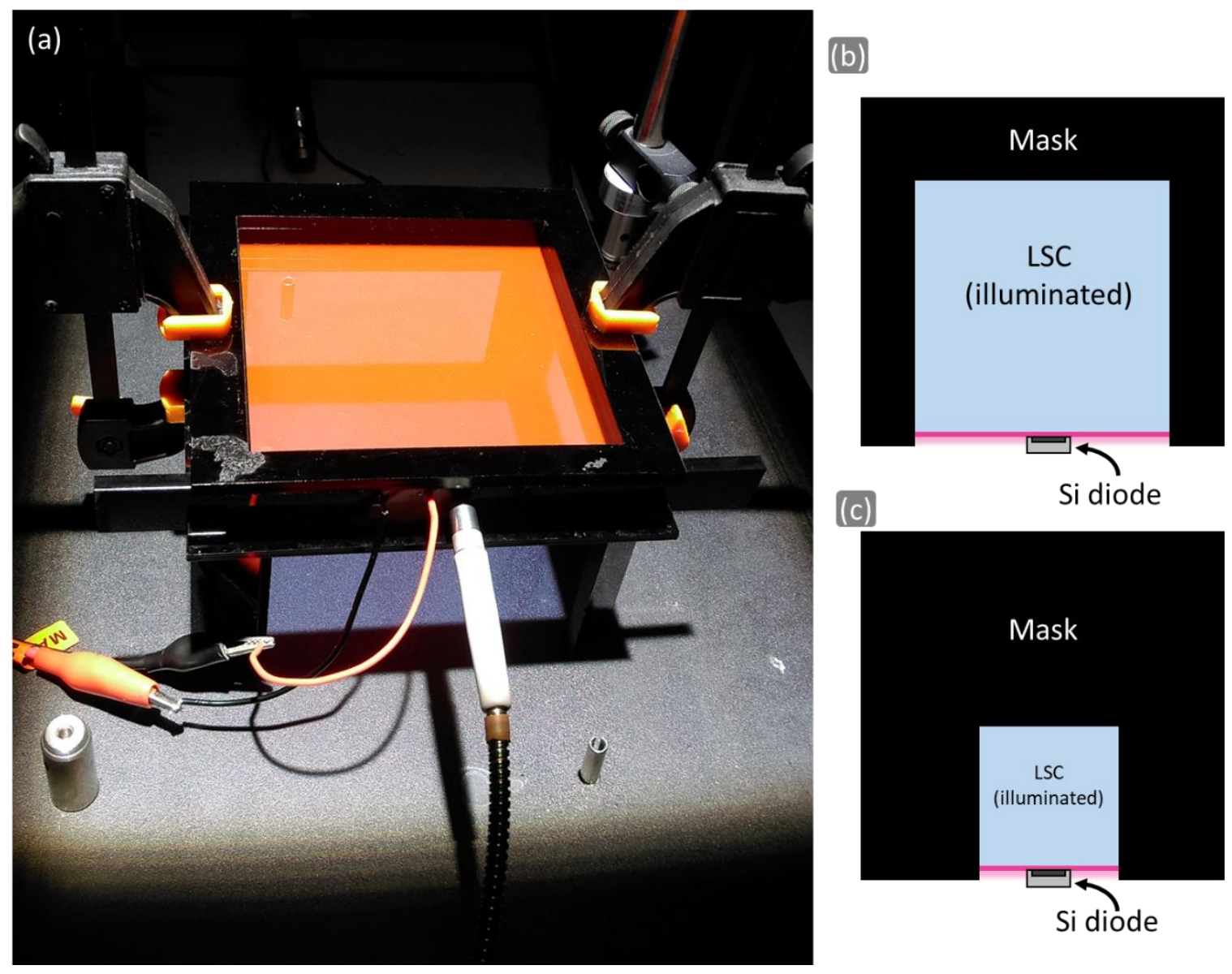

Figure S2 - (a) edge emission testing (with both Si diode and optical fibre connected to ocean optics spectrophotometer) and $(b, c)$ schematics of different tests for different illumination areas based on partial masking. 


\section{S4. Monte Carlo Modelling}

Monte Carlo (MC) simulations have previously been employed $[1,2]$ in order to determine optimal dye concentrations for LSCS, on account of the trade-off between light harvesting and reabsorption (where either thermalisation or emission at steep angles result in losses). There is no 'optimal' length or width for an LSC, nor is there a thickness as increases in either of these leads to a greater total photonic output, albeit with diminishing returns. On the other hand, smaller crosssectional areas will provide greater flux concentration factors (less light lost), however this requires more total PV area. Practically, economic and aesthetic considerations will play the major role in determining these values. MC modelling also allows us to readily 'forward plan' future dye development. For example, we can use it to see what could be achieved with a $10 \mathrm{~nm}$ larger stokes shift, or if the FQY was enhanced, giving researchers direction in terms of where further dye development efforts should be placed.

In this paper, we present a simple model (based upon Figure S1 above), along with its use in the optimisation of an LSC system for a BODIPY derivative and incorporation into a whole photovoltaic window. An area of $100 \times 100 \mathrm{~mm}$ was selected as an exposed area.
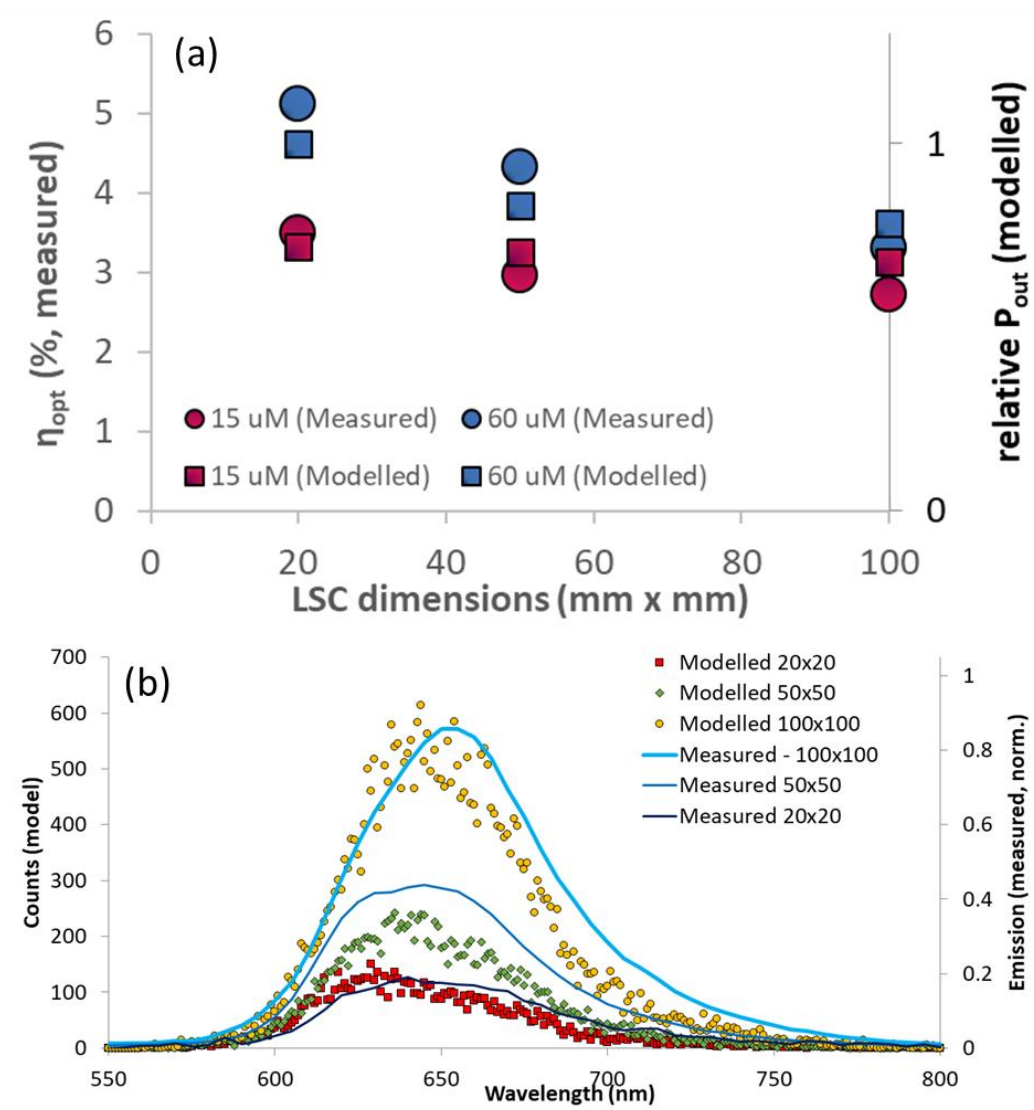

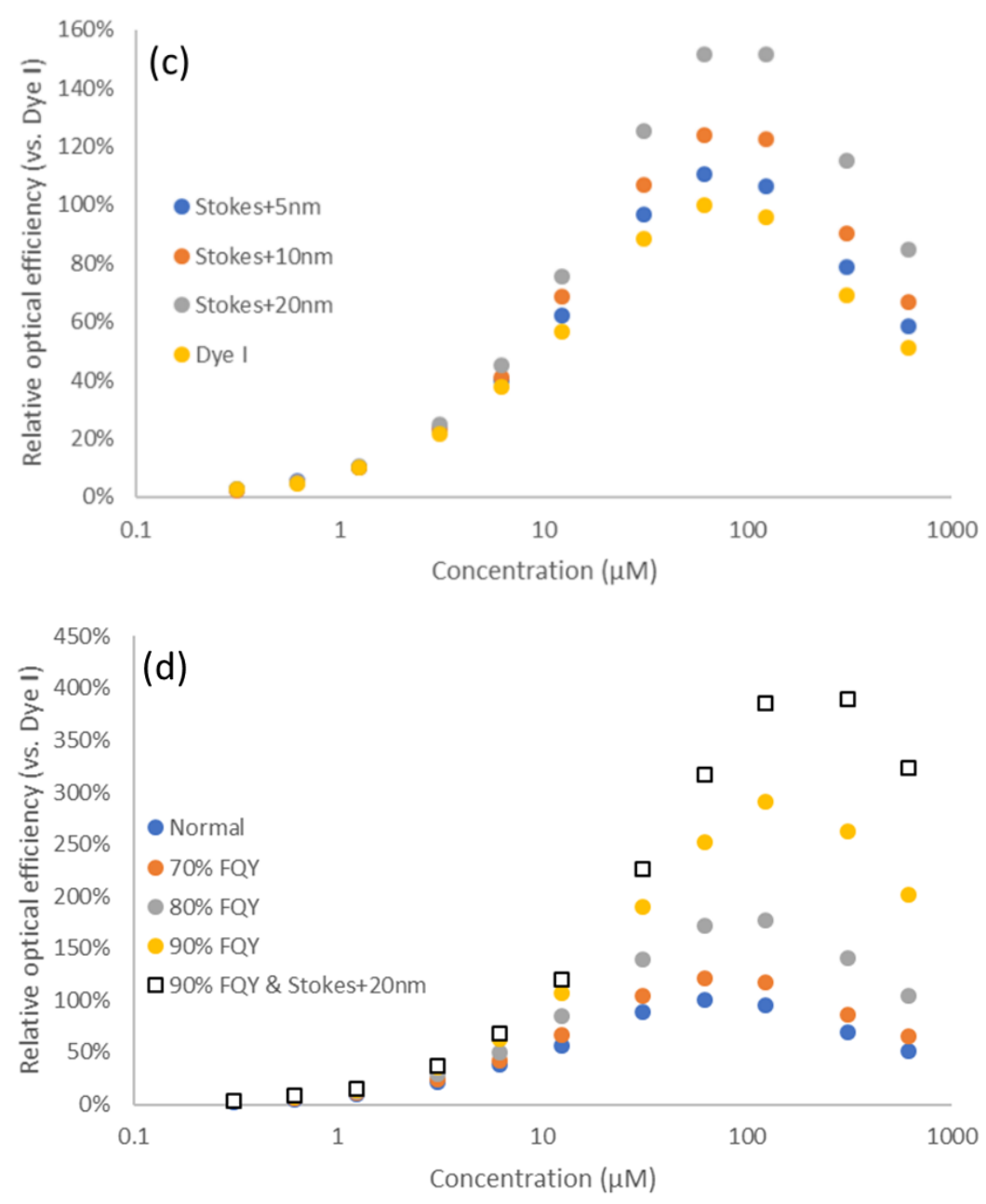

Figure $S 3-(a)$ relative power out calculated from $M C$ model and measured $\eta_{\text {opt. }}$. (b) Modelled versus experimentally obtained spectrally resolved output for three sizes of $15 \mu \mathrm{M}$ LSCs. Monte Carlo simulations of the relative optical efficiency expected for dyes similar to I but with (c) larger stokes shifts (simulated by red-shifting the emission), (d) enhanced fluorescence yields or both. 


\section{S4. LAB colorspce measurements of LSCS}

The LSCs were measured on both the Shimadzu 1800 spectrometer (Fig S4(a), with sequential wavelength probing) and using a HunterLab ColorQuest XE spectrophotometer (Fig S4(b)) with photodiode array). The transmission of the LSCS and a control of plain Perspex are shown, acquired from the two spectrometers respectively. It is clear that front/back face luminescence in the red/infrared part of the spectrum has in impact on the observed result (Figure S4(b)). Lab values, shown in the main text, are calculated from measurements performed on the ColorQuest XE.
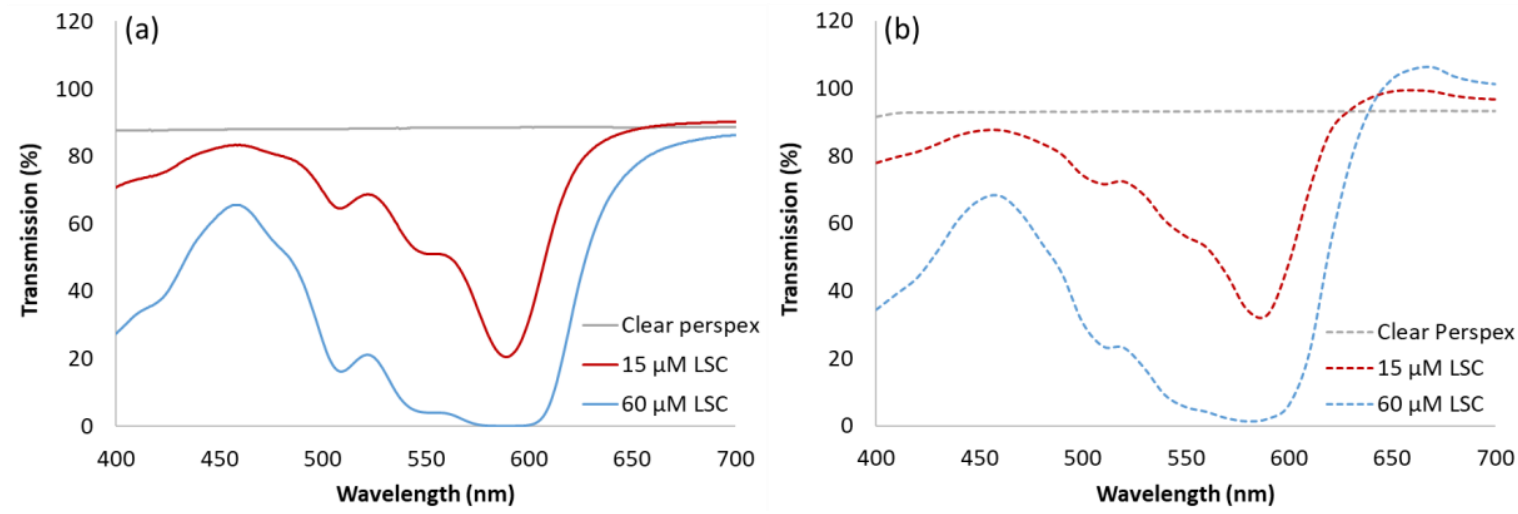

Figure S4 - (a) transmission as measured using Shimadzu 1800 spectrophotometer and (b) apparent transmission as measured using a HunterLab ColorQuest XE, noting the $>100 \%$ values where the LSC emits. 